\title{
Impact of modified soil thermal characteristic on the simulated monsoon climate over south Asia
}

\author{
Pankaj Kumar ${ }^{1, *}$, Ralf Podzun ${ }^{1, * *}$, Stefan Hagemann ${ }^{1}$ and Daniela Jacob ${ }^{1,2}$ \\ ${ }^{1}$ Max Planck Institute for Meteorology, Hamburg, Germany. \\ ${ }^{2}$ Climate Service Center, Hamburg, Germany. \\ *Corresponding author.e-mail: pankaj.kumar@mpimet.mpg.de
}

In the present study, the influence of soil thermal characteristics (STC) on the simulated monsoon climate over south Asia is analyzed. The study was motivated by a common warm temperature bias over the plains of northern India that has been noticed in several global and regional climate models. To address this warm bias and its relation to STC, two sensitivity experiments have been performed with the regional climate model REMO of the Max Planck Institute for Meteorology. The control experiment uses the standard soil thermal characteristic of the model that corresponds to a moist soil. The second experiment uses modified STC that characterize a dry soil, which is more representative of the considered region, as a large part of the region has arid, semi-arid or subtropical summer wet conditions. Both experiments were conducted over 20 years using re-analysis data as lateral boundary conditions. Results show that using the modified STC the predominant regional warm bias has reduced substantially, leading to a better and more realistic surface temperature compared to observations over south Asia. Although, the magnitude of bias has reduced, the warm bias still exists over the region suggesting that other atmospheric and land surface processes also play a role, such as aerosols and irrigation. These need to be addressed adequately in future modeling studies over the region.

\section{Introduction}

The monsoon is the most important climatic feature over south Asia. It is mainly characterized by seasonal reversal of wind from winter to summer and associated heavy precipitation over the region. During winter the circulation is easterly to northeasterly and in summer it is southerly to southwesterly. Nearly $20 \%$ of the world population lives in south Asia and the majority of people over the region depend on agriculture for their livelihood, which primarily depends on monsoon rainfall. During the summer monsoon season (June-September: hereafter referred as JJAS), India as a whole receives $70-90 \%$ of its annual rainfall (Rajeevan et al. 2006). October to May is more or less dry season, except during north-east monsoon (Kumar et al. 2007) when the south peninsular India, particularly the east coast, receives a good amount of rainfall. Monsoon rainfall has a strong influence on industrial and agricultural production, water resources, power generation and hence on the whole economy of the region. However, extreme monsoon rainfall may also bring destruction to the region and may cause thousands of lives to be lost or displaced due to several hundred kilometres of drowned land. In view of the socio-economic importance of south Asian monsoon, it is interesting to examine the climate predictability of this phenomenon using a high resolution regional climate model.

Keywords. Regional climate modelling; REMO; Indian summer monsoon; soil thermal characteristics.

** Since deceased. 
Climate modeling over south Asian region is a challenging task, as most of the models working well in other parts of the world fail drastically in simulating the climate of the south Asia monsoon region, due to highly complex interaction between land, ocean and atmosphere. Orography plays an important role in modulating the Indian summer monsoon rainfall (Li and Yanai 1996; Chakraborty et al. 2002; Boos and Kuang 2013). General circulation models (GCMs) studies are available with a focus on the Indian monsoonal region and most of them have concluded that GCMs have difficulties in simulating the mean monsoon climate of south Asia (Kang et al. 2002; Rajeevan and Nanjundiah 2009; Turner and Annamalai 2012; Kumar et al. 2013). Due to their coarse resolution $(\sim 200 \mathrm{~km})$ GCMs show limitations in simulating the complex orographic precipitation patterns. Developing high resolution climate models on a global scale is not only computationally expensive, but also suffers from errors due to inadequate representation of climate processes.

Regional climate modeling is a young field compared to global climate modeling with its presence mainly since early 1990s (Giorgi 1990) and studies over south Asia much later. The need of a regional climate model (RCM) is mostly felt to produce the fine scale climate signals for future climate change studies and for impact assessment groups, as GCMs provide useful climate change projections at continental scale of several thousand kilometres, but their projections at the regional scale, that is, several hundred kilometres or less, are considered less reliable (Giorgi et al. 2001).

Several RCM studies (Bhaskaran et al. 1996; Jacob and Podzun 1997; Ratnam and Kumar 2005; Das et al. 2006; Rupa Kumar et al. 2006; Saeed et al. 2009; Dobler and Ahrens 2010; Lucas-Picher et al. 2011; Kumar et al. 2013) have been carried out to simulate the summer monsoon over south Asia. All have reported an improvement in the simulation of spatial and temporal distribution compared to coarser global models, but also showed a general overestimation of orographic rainfall. Many climate model studies have shown a warm bias over south Asia monsoon region (Christensen et al. 2007). Koster et al. (2004) in a multi-model (12) global study have identified regions of strong coupling between soil moisture and precipitation. One such predominant region is noticed over the plains of northern India, which is visible in more than half of the models used in the study. In a follow up study Koster et al. (2006) have found that over such regions warm temperature bias is noticed in majority of the models used. In a recent multi-model (four) RCMs study, Lucas-Picher et al. (2011) have reported almost the same regime of warm bias over south Asia, except one model; meaning three out of four regional model showed warm temperature bias over the plains of northern India. The one model that did not show warm bias had an excess precipitation bias over the region, which may have led to a suppression of the warm bias.

Different processes may contribute to this warm bias. Aerosols and irrigation play an active role in modifying the local climate over the plains of northern India (Ramanathan et al. 2005; Siebert et al. 2005; Saeed et al. 2009; Lee et al. 2011). Siebert et al. (2005) have shown that over plains of northern India and northeast Pakistan, irrigation area is more concentrated to the northern parts of the plains. The warm bias noticed in the climate models is spread over a large part of south Asia with its maximum bias over the plains of northern India. The total irrigated area (Siebert et al. 2005) generally comprises less than $\sim 20 \%$ of the area in the warm bias region. In a sensitivity study, Anders and Rockel (2009) have shown that changing the soil type over Europe has improved the warm temperature bias (summer drying) over the region. This study has motivated us to perform sensitivity experiments over south Asia with modified soil thermal characteristics.

In the present study, the Max-Planck Institute for Meteorology REgional MOdel (REMO) has been used to simulate the south Asia monsoon system. Two sensitivity experiments have been performed using lateral boundary conditions from most of the recent re-analysis of the European Centre for Medium-range Weather Forecasts (ECMWF), ERA-Interim, at very high horizontal resolution. The first experiment was performed with the REMO standard version and the second with modified STC. The next section describes the data, model and experiment design. In section 3 , sensitivity experiments are discussed followed by discussion and lastly the summary is presented.

\section{Experiment design}

For our study, we used the regional climate model REMO (Jacob 2001, 2009). REMO is a three dimensional hydrostatic atmospheric circulation model, which solves the primitive equations of the atmospheric motion. REMO is a combination of two models, dynamical core and discretisation in space and time have been taken from the Europa Model from DWD and Physics has been taken from ECHAM4 (GCM of MPI-M; Roeckner et al. 1996). The atmospheric prognostic variables of REMO are horizontal wind components, temperature, pressure, specific humidity, and cloud liquid water content. The model uses the Arakawa-C grid for horizontal representation in which all variables except the 
wind component are defined in the centre of the respective grid box, and a hybrid of $\mathrm{p}$ and $\eta$ using 27 levels in vertical. The vertical discretisation follows Simmons and Burridge (1981). The temperature integration is accomplished by a leap frog scheme with semi-implicit and an explicit advection scheme. The lateral boundary interpolation uses the method of Davies (1976). The prognostic variables of REMO are adjusted towards the large scale forcing in a lateral sponge zone of 8 grid boxes in which the lateral boundary conditions (LBC) influence decreases exponentially towards the inner model domain.

The land surface scheme in REMO is taken from Dümenil and Todini (1992) and Hageman and Dümenil Gates (2003). The soil temperatures are calculated using the heat conduction diffusion equation solved in five different layers covering up to $10 \mathrm{~m}$ in the lower most soil (equation 1 ). In principle, land surface processes in REMO are derived from the parameterization scheme of ECHAM4 (Roeckner et al. 1996). The grid scale parameterization of cloud microphysics is based on the solution of the budget equations with the bulk scheme of Kesler (1969) and subgrid scale precipitation processes follow the Tiedtke (1989) convective scheme, with adjustments to Nordeng (1994). The surface mean orography is calculated from USGS GTOPO30 topography data. The seasonal cycle of vegetation is represented by monthly varying fields of LAI, fractional green vegetation cover (Rechid and Jacob 2006) and snow-free land surface albedo (Rechid et al. 2008a, b).

$$
\begin{aligned}
C \frac{\partial T}{\partial t} & =\frac{\partial}{\partial z}\left(\lambda \frac{\partial T}{\partial z}\right) \\
\frac{\partial T}{\partial t} & =a \cdot \frac{\partial^{2} T}{\partial z^{2}}
\end{aligned}
$$

where $a=\lambda / C ; C$ is the heat capacity; $\lambda$ is the heat conductivity; $a$ is the heat diffusivity; $T$ is the temperature of the soil layer; $t$ is the time step and $z$ is the depth of the respective soil layer.

Two experiments were performed (i) with model standard version and (ii) with modified STC. The lateral boundary conditions have been derived from the new ECMWF re-analysis (Dee et al. 2011) product ERA-Interim (hereafter referred as ERAI). Using ERAI forcing the model was run at a horizontal resolution of $0.25 \times 0.25(\sim 25 \mathrm{Km})$ for the period 1989-2008. The REMO soil spinup period over south Asia is nearly 20 years, so REMO was initially run for this spin-up period and then was re-run on climate mode. In the climate mode, the model has to be initialized once and uses surface parameters over land, SST over ocean and

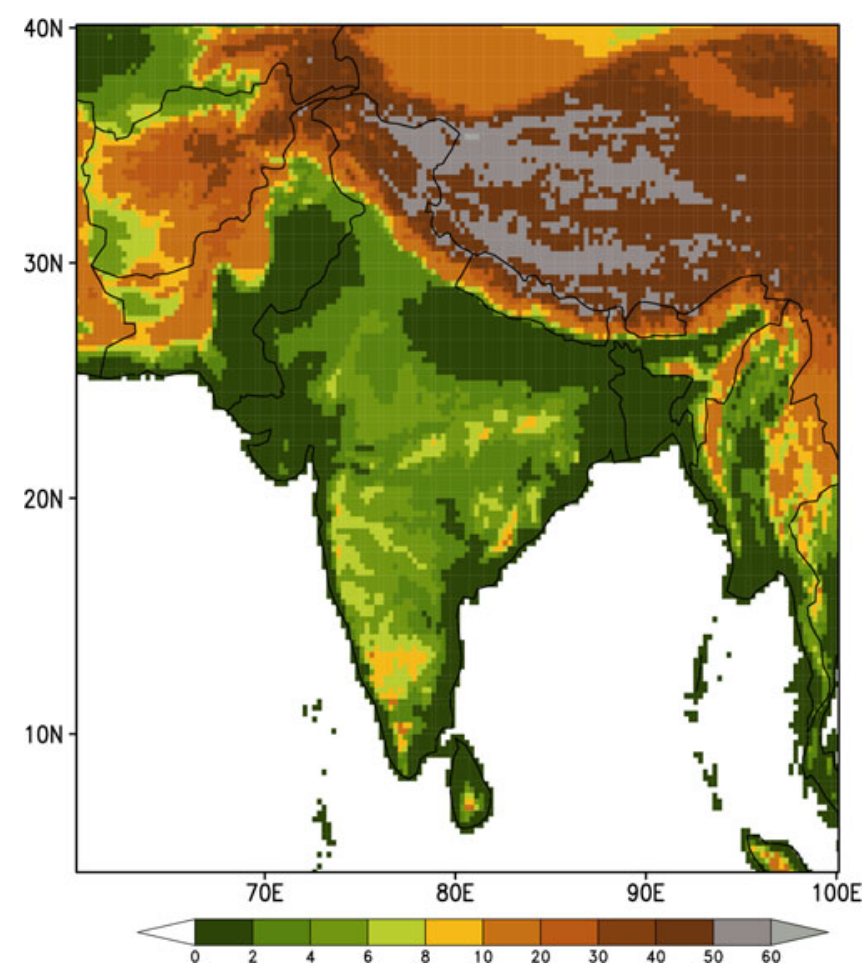

Figure 1. Simulation domain and topography (metre $* 10^{2}$ ) over south Asia.

varying lateral boundary values during the whole simulation. The update of lateral boundaries has a temporal resolution of 6 hours and is interpolated into a two minute time step. All the results presented in next section are for the monsoon season (JJAS). Figure 1 shows the model domain and topography over south Asia.

\section{Sensitivity experiments}

In REMO, the modified version of ECHAM4 soil hydrology is represented by a bucket type soil module following Hageman and Dümenil Gates (2003), where each grid box is represented by a single soil water reservoir, i.e., the depth of the bucket that is taken from Hagemann (2002). Therefore the water available for evaporation is defined by the rooting depth of the plants and the soil texture properties. With regard to soil thermal parameters (heat capacity and conductivity) that enter equation (1), REMO uses six general soil types (table 1 ) that are spatially distributed at the grid scale.

The first REMO sensitivity simulation over south Asia was performed with the standard REMO version (hereafter referred as $\mathrm{REMO}_{\text {Ref }}$ ) for the period 1989-2008. The model results when compared to 
Table 1. Standard and modified soil heat capacity and diffusivity values of REMO.

\begin{tabular}{lccccc}
\hline & \multicolumn{2}{c}{ REMO $_{\text {Ref }}$} & & \multicolumn{2}{c}{ REMO $_{\mathrm{Mfd}}$} \\
\cline { 2 - 3 } \cline { 5 - 6 } types & $\begin{array}{c}\text { Heat capacity } \\
\mathrm{J} /\left(\mathrm{m}^{3} * \mathrm{~K}\right)\end{array}$ & $\begin{array}{c}\text { Heat conductivity } \\
\mathrm{W} /(\mathrm{m} * \mathrm{~K})\end{array}$ & & $\begin{array}{c}\text { Heat capacity } \\
\mathrm{J} /\left(\mathrm{m}^{3} * \mathrm{~K}\right)\end{array}$ & $\begin{array}{c}\text { Heat conductivity } \\
\mathrm{W} /(\mathrm{m} * \mathrm{~K})\end{array}$ \\
\hline Sand & $1.93 \mathrm{E}+06$ & $8.7 \mathrm{E}-7$ & & $1.28 \mathrm{E}+06$ & $2.34 \mathrm{E}-7$ \\
Sand loam & $2.10 \mathrm{E}+06$ & $8.0 \mathrm{E}-7$ & & $1.35 \mathrm{E}+06$ & $2.07 \mathrm{E}-7$ \\
Loam & $2.25 \mathrm{E}+06$ & $7.4 \mathrm{E}-7$ & & $1.42 \mathrm{E}+06$ & $1.76 \mathrm{E}-7$ \\
Clay loam & $2.36 \mathrm{E}+06$ & $7.1 \mathrm{E}-7$ & & $1.5 \mathrm{E}+06$ & $1.4 \mathrm{E}-7$ \\
Clay & $2.48 \mathrm{E}+06$ & $6.7 \mathrm{E}-7$ & & $1.63 \mathrm{E}+06$ & $1.1 \mathrm{E}-7$ \\
Peat & $2.59 \mathrm{E}+06$ & $6.5 \mathrm{E}-7$ & & $0.58 \mathrm{E}+06$ & $1.03 \mathrm{E}-7$ \\
\hline
\end{tabular}

observational data CRU (Brohan et al. 2006; version CRUv3.1) show a strong positive bias of $2 \mathrm{~m}$ temperature $\left(\sim 2^{\circ} \mathrm{C}\right.$ to $\left.\sim 8^{\circ} \mathrm{C}\right)$ covering almost the entire model domain (figure $2 \mathrm{a}$ and $\mathrm{c}$ ). The maximum bias was noticed over the monsoon heat low area (Bollasina and Nigam 2011) and Arabia up to $8^{\circ} \mathrm{C}$ extended over major parts of plains of northern India. Here it is evident that the model has some deficiencies in simulating the mean monsoon climate. Anders and Rockel (2009) have reported for Europe that soil type plays an important role in modulating the regional climate. In the standard soil thermal parameterization of REMO, heat conductivity and capacity are parameterized as a function of soil moisture. This parameterization uses external constants as reference values independent of soil moisture. In the standard REMO version, these reference values represent values of a medium moist soil (mid latitude rainy climate). However, climate over south Asia is mainly dry as large part of the domain falls under arid, semi-arid or subtropical wet summer climate (Jacob et al. 2012). In the modified simulation we have changed the reference values of the soil thermal characteristic to represent dry soil. Therefore STC has been adjusted from a medium moist type to dry type (Gordon 2002) by changing the reference values (table 1) of heat conductivity and capacity. With changed soil heat diffusivity (= heat conductivity/heat capacity), a second REMO simulation was performed (hereafter referred as $\mathrm{REMO}_{\mathrm{Mfd}}$ ) for the same period.

The $\mathrm{REMO}_{\mathrm{Mfd}}$ simulation shows a realistic improvement in $2 \mathrm{~m}$ temperature while compared to $\mathrm{REMO}_{\text {Ref }}$ and CRU data figure 2 (panels a, b, and d). The warm bias dropped by $\sim 1.5^{\circ} \mathrm{C}$ to $\sim 4^{\circ} \mathrm{C}$ over major parts of the biased region noticed in the reference simulation. This suggests that the modified STC led to a better simulation of the temperature over south Asia. However, a cold bias $\left(1^{\circ}-\right.$ $2^{\circ} \mathrm{C}$ ) is noticed over the peninsular India (figure not shown). The bias in temperature is closely connected to a bias in mean sea level pressure (MSLP) in $\mathrm{REMO}_{\text {Ref }}$ simulation, as simulated MSLP is
2-4 hPa less than in ERAI. However, the model is able to produce the mean position and the magnitude of the minimum low pressure over the monsoon heat low area with gradual decrease towards the southeast up to Bay of Bengal and the north south gradient is well simulated compared to ERAI (figure $3 \mathrm{a}$ and c). REMO $\mathrm{Mfd}_{\mathrm{d}}$ simulation has shown an improvement over the biased region (figure $3 \mathrm{a}, \mathrm{b}$ and $\mathrm{d}$ ) by $1 \mathrm{hPa}-2 \mathrm{hPa}$, suggesting that the reduced warm bias has resulted in an improved MSLP bias, though, MSLP magnitude is still less compared to ERAI over the biased region.

Precipitation is not only one of the most important results over south Asia, but also the most complicated variable to be simulated. Over south Asia spatial pattern of precipitation is characterized by high precipitation over the wind-ward side (west coast of India, Myanmar, and foot hills of Himalayas), land rainfall maxima over Bangladesh extended up to central India and rain shadow area (lee ward side) over east coast of India as well as minimal precipitation over NW India and Pakistan. In both experiments, the model is able to simulate these major rainfall regimes quite well, e.g., excess precipitation over west coast of India and then sharp decrease towards the east coast, land maxima, high precipitation over foot hill of Himalaya compared to CRU data figure 4 (panels a, b and c). However the model has some noticeable limitations too, as it is simulating nearly 1-2 $\mathrm{mm} / \mathrm{d}$ less precipitation over the temperature and MSLP biased region, i.e., over the plains of northern India. Though both temperature and MSLP have shown improvement with the modified STC simulation, there is no clear signal for improved precipitation over the plains of northern India and Pakistan as both simulations show low precipitation intensities compared to CRU. Considering the circulation pattern at $850 \mathrm{hPa}$ (figure not shown), it is evident that in both simulations south-westerlies over the Arabian Sea are more northerly stretched (may be due to a too strong land sea contrast) compared to ERAI (figures 2 and 3) and hence result in a weak Somali jet. 

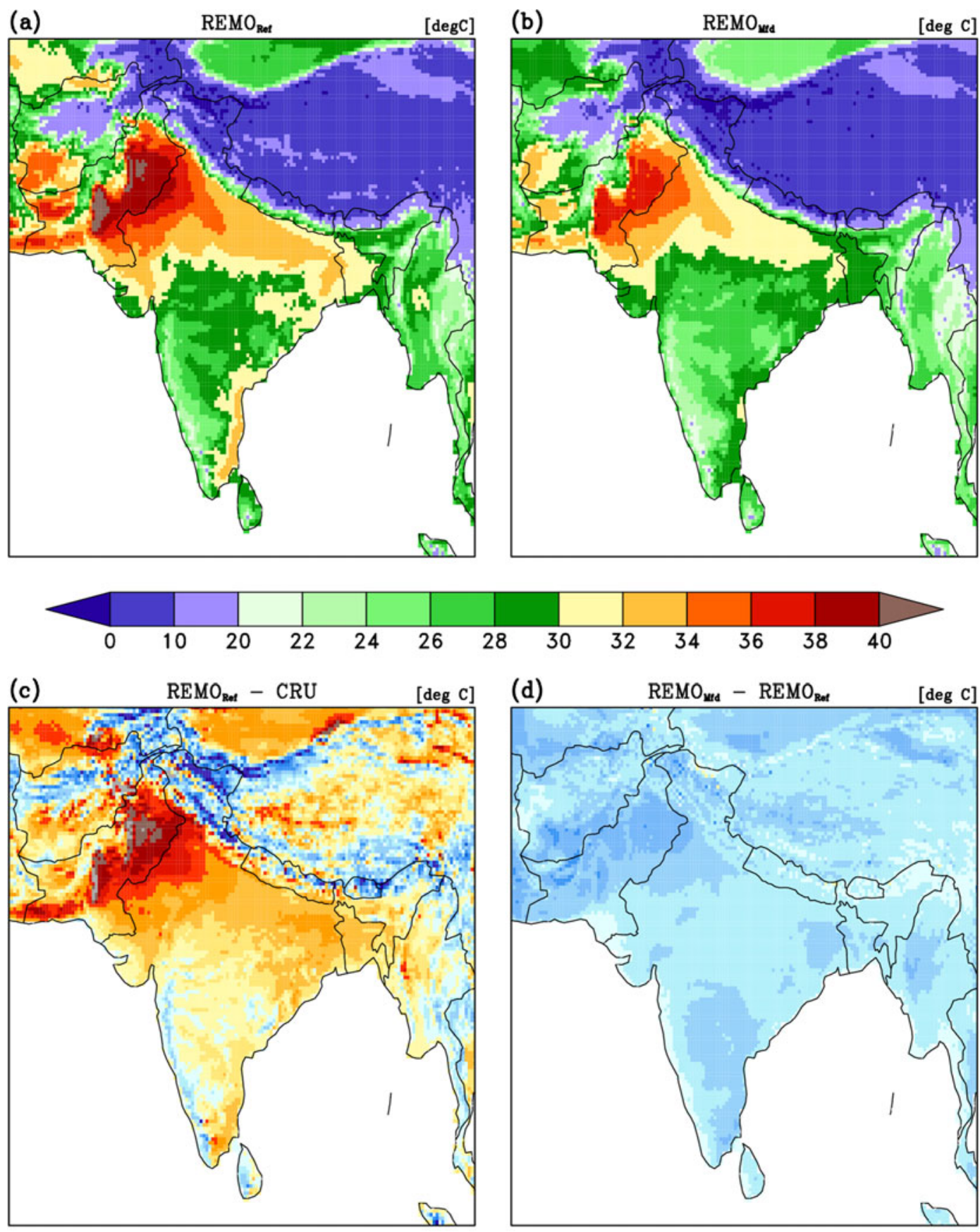

(d) $\mathrm{REMO}_{\text {wdd }}-\mathrm{REMO}_{\text {Ret }} \quad$ [deg C]

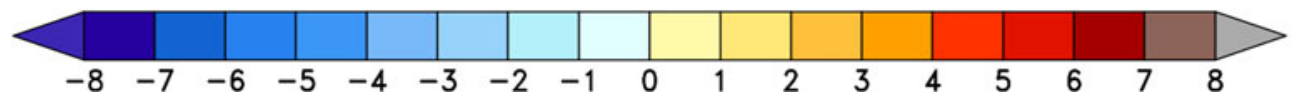

Figure 2. Spatial maps of June-September climatology of $2 \mathrm{~m}$ temperature simulated by REMO. Panel (c) shows the difference between $\mathrm{REMO}_{\mathrm{Ref}}$ and observations $\mathrm{CRU}$ in ${ }^{\circ} \mathrm{C}$, for the period 1989-2008. The panel (d) shows the difference between the $\mathrm{REMO}_{\mathrm{Mfd}}$ and $\mathrm{REMO}_{\mathrm{Ref}}$ simulation.

This weak moisture laden south-westerly dumps most of the moisture over the central and peninsular India where the model has an excess precipitation bias compared to observations, which in turn contributes to a cold bias in temperature. Whereas, over Bay of Bengal both REMO simulations show strong wind anomalies compared to ERAI. This possibly leads to a wet precipitation bias over the region and it also drags away some moisture from the Bay of Bengal to further east, and hence decreases precipitation anomalies over Bangladesh and plains of northern India. Also the low MSLP anomalies over the monsoon heat low area lead to an enhanced gradient towards Arabia resulting in mixing of dry winds from Arabia. This enhanced dry wind opposes the moist current from 

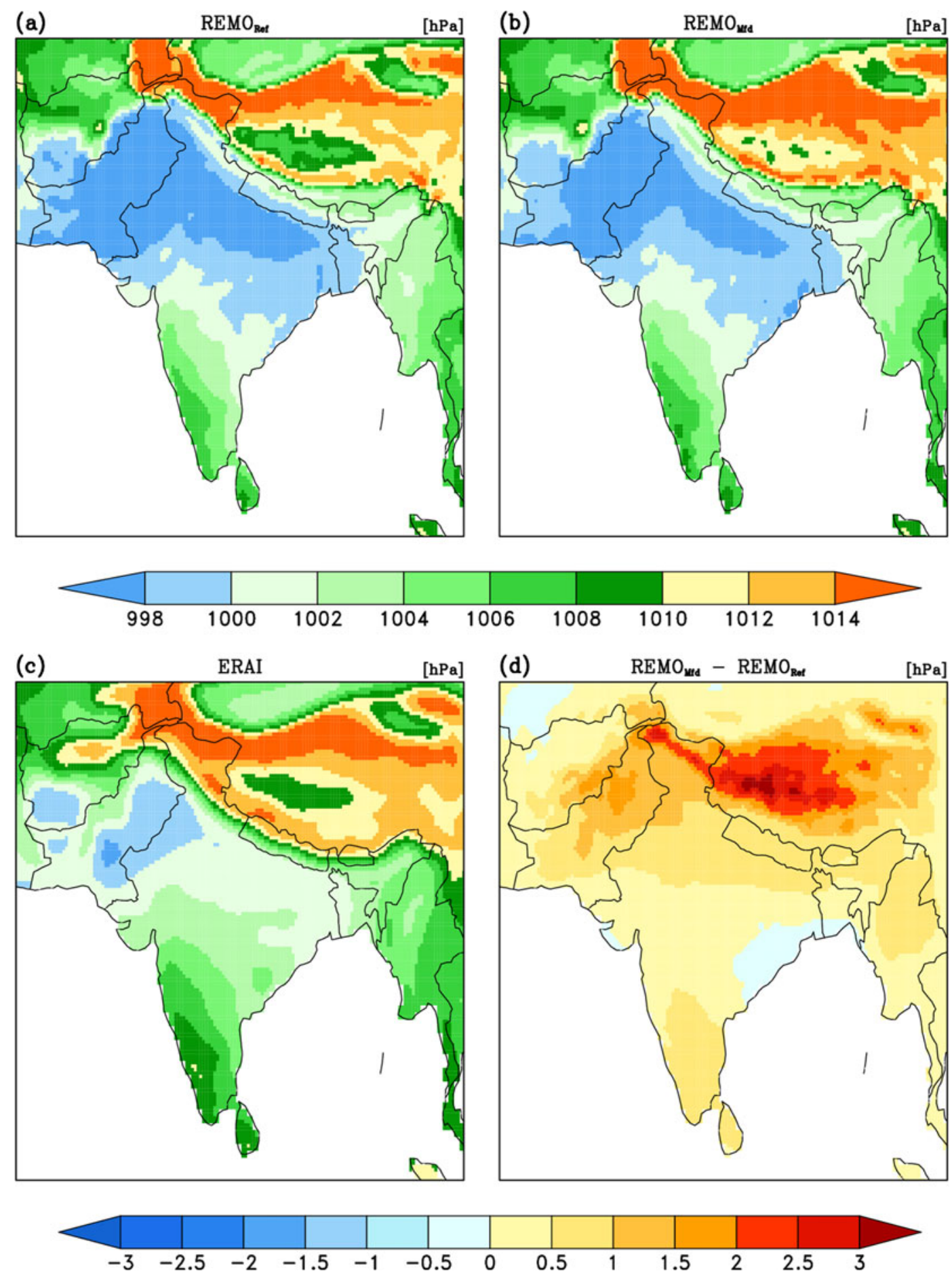

Figure 3. Spatial maps of June-September climatology of mean sea level pressure simulated by REMO and observations ERA-Interim in hPa, for the period 1989-2008. The panel (d) shows the difference between the $\mathrm{REMO}_{\mathrm{Mfd}}$ and REMORef simulation.

the Bay of Bengal branch and hence suppresses the precipitation intensities over the biased region contributing to deficient precipitation intensities over the plains of northern India and NE Pakistan.

Ramanathan et al. (2005) have conducted a series of simulations with observed aerosols radiative forcing over India. They argue that the absorbing aerosols of atmospheric brown clouds have modified the regional climate and hydrological cycle and have masked the regional warming by at least $50 \%$. Since in REMO aerosols are not explicitly simulated, the recent reduction in surface temperature is not noticed in the REMO simulations, which likely contributes to the warm bias over India. Also, Saeed et al. (2009) have reported that this warm bias is due to missing irrigation process in REMO. In their 

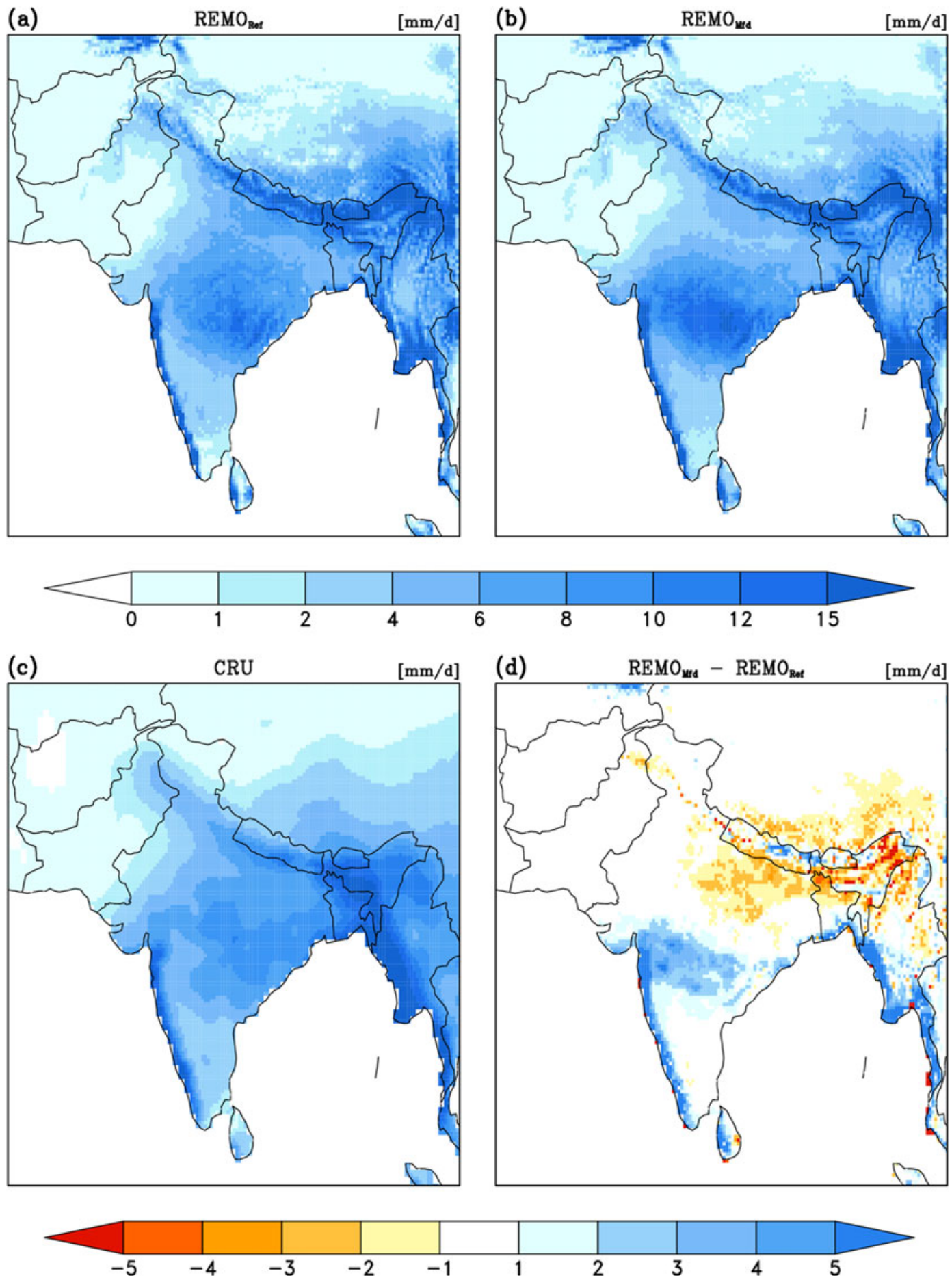

Figure 4. Spatial maps of June-September climatology of precipitation intensities simulated by REMO for the period 19892008 and observations CRU for the period 1989-2007 in mm/d. The panel (d) shows the difference between the REMO ${ }_{\mathrm{Mfd}}$ and $\mathrm{REMO}_{\text {Ref }}$ simulation.

sensitivity study they have concluded that introducing artificial moisture over the plains of northern India has improved the simulated monsoon climate. Consequently we infer from this that the remaining warm bias over the region could be removed by an adequate representation of aerosols and irrigation within the REMO model, which would further improve the simulated monsoon climate.

\section{Discussion}

We have explored details about which physical processes are contributing to a better monsoon climate using the modified STC.

Dry soil is associated with reduced water availability within the soil. The resulting lower diffusivity values allow for lower heat transport within 


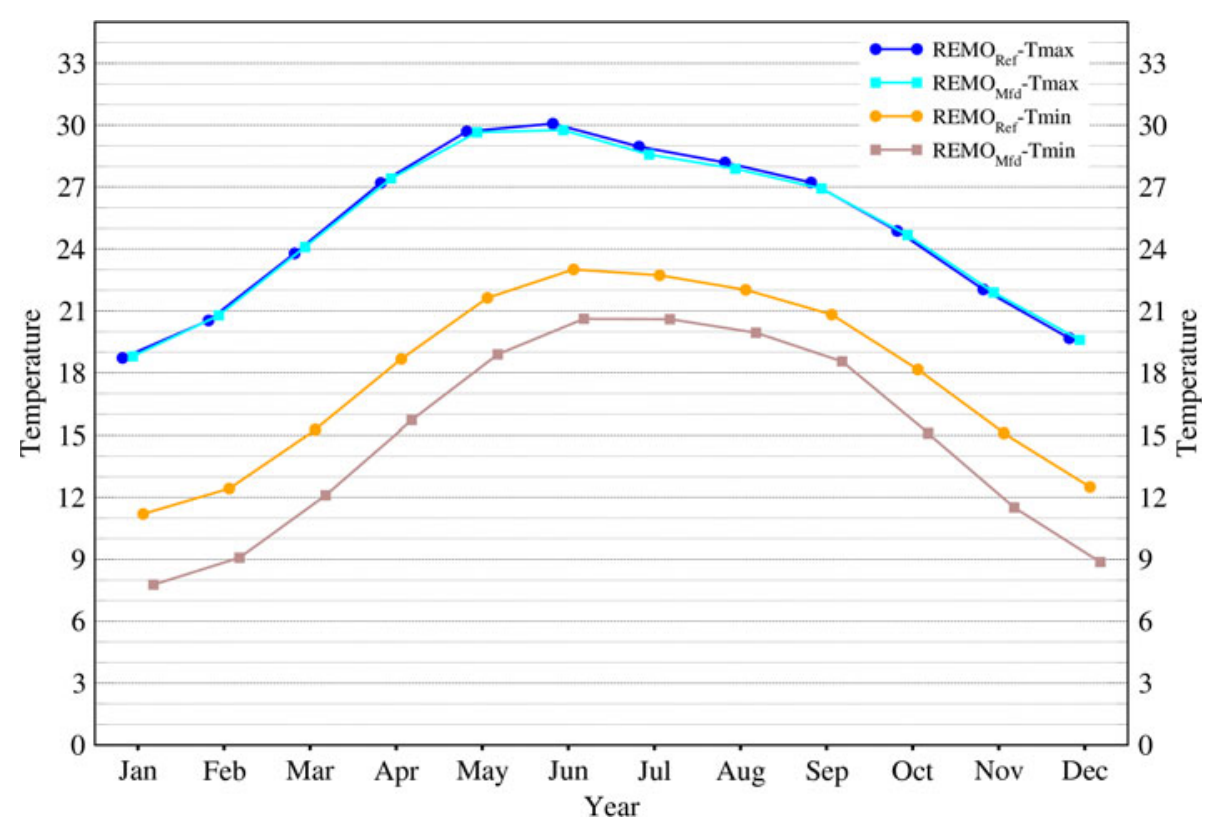

Figure 5. Mean annual cycle of $\mathrm{T}_{\mathrm{MAX}}$ and $\mathrm{T}_{\mathrm{MIN}}\left({ }^{\circ} \mathrm{C}\right)$ simulated by $\mathrm{REMO}_{\mathrm{Mfd}}$ and $\mathrm{REMO}_{\text {Ref }}$ for the period $1989-2008$.

the soil and vice versa. Thus, decreased values mean that, especially during daytime the energy from the heated surface can be transported downwards less fast. At night less heat will be transported upwards within the soil to warm the cool surface, thus the surface stays cooler and temperatures are decreased. Figure 5 shows the mean annual cycle of monthly means of $\mathrm{T}_{\mathrm{MAX}}$ and $\mathrm{T}_{\mathrm{MIN}}$ for $\mathrm{REMO}_{\mathrm{Mfd}}$ and $\mathrm{REMO}$ Ref. For $\mathrm{REMO}_{\mathrm{Mfd}}$ significant changes are noticed in $\mathrm{T}_{\mathrm{MIN}}$ up to $2^{\circ}-3^{\circ} \mathrm{C}$ in all months and minor changes in $\mathrm{T}_{\mathrm{MAX}}$. Maximum effect is noticed in $\mathrm{T}_{\text {MIN }}$ not in $\mathrm{T}_{\mathrm{MAX}}$, though increase in $\mathrm{T}_{\mathrm{MAX}}$ is also expected as during the day less heat is transported within the soil. To explore this aspect, diurnal cycles of surface energy balance are explored. In REMO, thermal radiation is parameterized as a function of surface temperature (Stefan Boltzmann law) so that a reduced surface temperature leads to a lower thermal radiation. With respect to $\mathrm{REMO}_{\text {Ref }}$ diurnal cycle of net surface solar radiation (short wave) shows a reduction of energy during daytime and no change in night as expected. Though, diurnal cycle of evaporation shows a decrease, during daytime an increase in skin reservoir content (water available on leafs and top of ground surface) and in soil wetness was noticed. Despite less evaporation, more cloud cover (5-7\%) occurred. The formation of cloud cover not only depends on evaporation but also on other stability parameters. Here, presumably convection is triggered and enhanced by increase in sensible heat flux, which in turn leads to more clouds. More clouds lead to less shortwave radiation and, thus, cause a negative feedback to the surface temperature warming, possibly resulting in the weak effect of changed STC on day surface temperature. Thus maximum effect of changed STC is noticed over $\mathrm{T}_{\mathrm{MIN}}$. Figure 2 (panel d) shows that the JJAS $2 \mathrm{~m}$ temperature in $\mathrm{REMO}_{\mathrm{Mfd}}$ is significantly colder than in $\mathrm{REMO}_{\text {Ref }}$ over the whole model domain. Much of the changes are noticed over the plains of northern India, and Pakistan, which mainly fall under the arid and semi-arid climate zone. As mentioned before, we have actually implemented the modified STC to represent the soil conditions in this climate zone.

However, the model is showing a cold bias over peninsular India, where more precipitation is simulated than observed, and the region is not covered under arid or semi-arid category (Jacob et al. 2012). The annual spatial pattern (not shown) looks very similar to JJAS with some variations in the rest of the other seasons. Thus, setting the STC for dry soil over the whole domain and for the entire season will not be adequate for future climate simulations. Here, further refinements of the model STC are needed to improve their representation, e.g., by improving the formulation of the STC. The aim of the present study is to highlight the importance of an adequate representation of STC over the complex model domain of south Asia.

\section{Summary}

The REMO model of MPI-M is widely used and successfully tested over various parts of the world for regional climate change studies, however over south Asia only a few studies exist. In a regional climate model intercomparison study over south 
Asia, Lucas-Picher et al. (2011) have shown that almost all the models used in the study have a warm bias especially over the plains of northern India that is usually further extended in the northwest direction. From Anders and Rockel (2009), it is known that soil thermal characteristics can have a major influence on the simulated climate over specific regions. In the standard REMO version the STC are defined for medium moist climate whereas large part of the south Asia domain falls under semi-arid, arid zone or subtropical summer wet. Therefore, STC have been modified from a moist to a dry type by modifying the heat conductivity and capacity in the soil moisture dependent parameterization. Then, REMO was simulated with and without the modified STC over south Asia. With the modified STC, the warm bias has substantially reduced, thereby leading to a better spatial pattern of MSLP. This resulted in a better land-sea gradient and consequently to a much more realistic $2 \mathrm{~m}$ temperature. However, with the modified STC the model has improved more than $50 \%$ of warm bias over the well-known regional warm bias region (Lucas-Picher et al. 2011) but still has a spatial bias of $1^{\circ}-3^{\circ} \mathrm{C}$ compared to $\mathrm{CRU}$ data. This suggests that other atmospheric and land surface processes also play an important role in modulating the south Asian summer monsoon climate, which is neither sufficiently represented in the current REMO version nor in other RCMs (cf. Lucas-Picher et al. 2011). These processes certainly comprise aerosols and irrigation (Ramanathan et al. 2005; Saeed et al. 2009), and need to be addressed in future studies to fully understand their impact on the south Asian summer monsoon climate.

\section{Acknowledgements}

This research was undertaken as part of the Integrated Project called 'HighNoon: Adaptation to changing water resources availability in Northern India with Himalayan glacier retreat and changing monsoon'. This project is funded by the European Commission, FP7, and contract number 227087. The authors acknowledge German Climate Computing Center (DKRZ) providing CPU time for REMO simulations. They also thank Tanja Blome from MPI-M for helpful discussions on soil temperature processes and their parameterization.

\section{References}

Anders I and Rockel B 2009 The influence of prescribed soil type distribution on the representation of present climate in a regional climate model; Clim. Dyn. 33(2-4) 177-186.
Bhaskaran B, Jones R G, Murphy J M and Noguer M 1996 Simulations of the Indian summer monsoon using a nested regional climate model: Domain size experiments; Clim. Dyn. 12 573-587.

Brohan P, Kennedy J J, Harris I, Tett S F B and Jones P D 2006 Uncertainty estimates in regional and global observed temperature changes: A new dataset from 1850; J. Geophys. Res. 111 D12106, doi: 10.1029/2005JD006548.

Bollasina M and Nigam S 2011 The summertime 'heat' low over Pakistan/northwestern India: Evolution and origin; Clim. Dyn. 37 957-970.

Boos W R and Kuang Z 2013 Sensitivity of the south Asian monsoon to elevated and non-elevated heating; Nature Scientific Reports 3 1192, doi: 10.1038/srep01192.

Chakraborty A, Nanjundiah R S and Srinivasan J 2002 Role of Asian and African orography in Indian summer monsoon; Geophys. Res. Lett. 29(20) 1989, doi: 10.1029/ 2002GL015522.

Christensen J H, Hewitson B, Busuioc A, Chen A, Gao X, Held I, Jones R and Kolli R K et al. 2007 Regional Climate Projections, Chapter 11; In: Climate Change 2007: The Physical Science Basis. Contribution of Working Group I to the Fourth Assessment Report of the Intergovernmental Panel on Climate Change (eds) Solomon S, Qin D, Manning M, Chen Z, Marquis M, Averyt K B, Tignor M and Miller H L, Cambridge University Press, Cambridge, UK and New York, USA.

Das S K, Shekhar M S and Singh G P 2006 Simulation of Indian summer monsoon circulation and rainfall using RegCM3; Theor. Appl. Climatol. 86 161-172.

Davies H C 1976 A lateral boundary formulation for multilevel prediction models; Quart. J. Roy. Meteorol. Soc. 102 405-418.

Dee D P, Uppala S M, Simmons A J, Berrisford P, Poli P and Kobayashi S et al. 2011 The ERA-interim reanalysis: Configuration and performance of the data assimilation system; Quart. J. Roy. Meteorol. Soc. 137 553-597, doi: $10.1002 /$ qj. 828 .

Dobler A and Ahrens B 2010 Analysis of the Indian summer monsoon system in the regional climate model COSMOCLM; J. Geophys. Res. 115 D16101, doi: 10.1029/ 2009JD013497.

Dümenil L and Todini E 1992 A rainfall-runoff scheme for use in the Hamburg climate model; In: Advances in Theoretical Hydrology: A Tribute to James Dooge (ed.) O'Kane J P, European Geophysical Society Series on Hydrological Sciences (Amsterdam: Elsevier Press), pp. 129-157.

Giorgi F 1990 Simulation of regional climate using a limited area model nested in a general circulation model; J. Climate 3 941-963.

Giorgi F et al. 2001 Regional Climate Information evaluation and projection. Climate Change; The Scientific Basis, Contribution of Working Group I to the Third Assessment report of IPCC.

Gordon B 2002 Ecological climatology: Concepts and applications; Cambridge University Press, 678p.

Hagemann S 2002 An improved land surface parameter dataset for global and regional climate models; Report 336, Max-Planck-Institute for Meteorology, Hamburg.

Hageman S and Dümenil Gates L 2003 Improving a subgrid runoff parameterization scheme for climate models by the use of high resolution data derived from satellite observations; Clim. Dyn. 21 349-359.

Jacob D 2001 A note to the simulation of the annual and interannual variability of the water budget over the Baltic Sea drainage basin; Meteorol. Atmos. Phys. 77(1-4) 61-74. 
Jacob D 2009 Regional Climate Models: Linking global climate change to local impacts; The Springer Encyclopedia of Complexity and Systems Science, pp. 7591-7602.

Jacob D and Podzun R 1997 Sensitivity studies with the Regional Climate Model REMO; Meteor. Atmos. Phys. 63 119-129.

Jacob D et al. 2012 Assessing the transferability of the Regional Climate Model REMO to different COordinated Regional Climate Downscaling EXperiment (CORDEX) Regions; Atmosphere 3 181-199.

Kang I S, Jin K, Wang B, Lau K M, Shukla J, Krishnamurthy V, Schubert S D, Wailser D E, Stern W F, Kitoh A, Meehl G A, Kanamitsu M, Galin V Y, Satyan V, Park C K and Liu Y 2002 Intercomparison of the climatological variations of Asian summer monsoon precipitation simulated by 10 GCMs; Clim. Dyn. 19 383-395.

Kesler E 1969 On the distribution and continuity of water substance in atmospheric circulations; Meteor. Monogr. 3284 .

Koster R D et al. 2004 Regions of strong coupling between soil moisture and precipitation; Science 305(5687) 1138-1140.

Koster R D et al. 2006 GLACE: The global landatmosphere coupling experiment. Part I: Overview; J. Hydromet. 7(4) 590-610.

Kumar P, Kumar K R, Rajeevan M and Sahai A K 2007 On the recent strengthening of the relationship between ENSO and northeast monsoon rainfall over south Asia; Clim. Dyn. 28 649-660.

Kumar P, Wiltshire A, Mathison C, Asharaf S, Ahrens B, Lucas-Picher P, Christensen J H, Gobiet A, Saeed F, Hagemann S and Jacob D 2013 Down scaled climate change projections with uncertainty assessment over India using a high resolution multi-model approach; Sci. Total Environ. 468-469 S18-S30, doi: 10.1016/ j.scitotenv.2013.01.051.

Lee E, Sacks W J, Chase T N and Foley J A 2011 Simulated impacts of irrigation on the atmospheric circulation over Asia; J. Geophys. Res. 116 D08114, doi: 10.1029/ 2010JD014740.

Li Chengfeng and Michio Yanai 1996 The onset and interannual variability of the Asian summer monsoon in relation to land-sea thermal contrast; J. Climate $9358-$ 375, doi: 10.1175/1520-0442(1996)009<0358:TOAIVO> 2.0.CO;2.

Lucas-Picher P, Christensen J H, Saeed F, Kumar P, Asharaf S, Ahrens B, Wiltshire A, Jacob D and Hagemann S 2011 Can regional climate models represent the Indian Monsoon?; J. Hydrometeor. 12 849-868.

Nordeng T E 1994 Extended versions of the convective parametrization scheme at ECMWF and their impact on the mean and transient activity of the model in the tropics; ECMWF Research Department, Technical Memoran- dum No. 206, October 1994, European Centre for Medium Range Weather Forecasts, Reading, UK, 41p.

Ramanathan V, Chung C, Kim D, Bettge T, Buja L, Kiehl J T, Washington W M, Fu Q, Sikka D R and Wild M 2005 Atmospheric brown clouds: Impacts on south Asian climate and hydrological cycle; PNAS 102(15) 5326-5333, doi: $10.1073 /$ pnas.0500656102.

Rajeevan M et al. 2006 High resolution daily gridded rainfall data for the Indian region: Analysis of break and active monsoon spells; Curr. Sci. 91(3) 296-306.

Rajeevan M and Nanjundiah R S 2009 Coupled model simulations of 20th century climate of the Indian summer monsoon; Current Trends in Science: Platinum Jubilee Special (ed.) Mukunda N, Indian Academy of Sciences, pp. $537-568$.

Ratnam J V and Kumar K K 2005 Sensitivity of the simulated monsoons of 1987 and 1988 to convective parameterization scheme in MM5; J. Climate 18 2724-2743.

Rechid D and Jacob D 2006 Influence of monthly varying vegetation on the simulated climate in Europe; Meteorol. Z. 15 99-116.

Rechid D, Raddatz T J and Jacob D 2008a Parameterization of snow-free land surface albedo as a function of vegetation phenology based on MODIS data and applied in climate modeling; Theor. Appl. Climatol. 95 245-255, doi: 10.1007/s00704-008-0003-y.

Rechid D, Hagemann S and Jacob D 2008b Sensitivity of climate models to seasonal variability of snow-free land surface albedo; Theor. Appl. Climatol. 95 197-221, doi: 10.1007/s00704-007-0371-8.

Roeckner E et al. 1996 The atmospheric general circulation model ECHAM-4: Model description and simulation of present-day climate; Max Planck Institute for Meteorology, Report No. 218.

Rupa Kumar K et al. 2006 High-resolution climate change scenarios for India for the 21st century; Curr. Sci. 90(3) $334-345$.

Saeed F, Hagemann S and Jacob D 2009 Impact of irrigation on the south Asian summer monsoon; Geophys. Res. Lett. 36 L20711.

Siebert S, Döll P, Hoogeveen J, Faures J M, Frenken K and Feick S 2005 Development and validation of the global map of irrigation areas; Hydrol. Earth Syst. Sci. 9 535-547, doi: 10.5194/hess-9-535-2005.

Simmons A J and Burridge D M 1981 An energy and angular momentum conserving vertical finite-difference scheme and hybrid vertical coordinates; Mon. Weather Rev. 109 758-766.

Tiedtke M 1989 A comprehensive mass flux scheme for cumulus parameterization in large scale models; Mon. Weather Rev. 117 1779-1800.

Turner A G and Annamalai H 2012 Climate change and the south Asian summer monsoon; Nature Climate Change $\mathbf{2}$ 587-595, doi: 10.1038/nclimate1495. 